\title{
Barium isotope fractionation in the global barium cycle: First evidence from barium minerals and precipitation experiments
}

\author{
Katja von Allmen ${ }^{\mathrm{a}}$, Michael E. Böttcher ${ }^{\mathrm{b}, *}$, Elias Samankassou ${ }^{\mathrm{a}, 1}$, Thomas F. Nägler ${ }^{\mathrm{c}, *}$ \\ a Department of Geosciences, Chemin du Musée 6, University of Fribourg, $\mathrm{CH}-1700$ Fribourg, Switzerland \\ ${ }^{\mathrm{b}}$ Leibniz Institute for Baltic Sea Research, Geochemistry \& Stable Isotope Geochemistry Group, Marine Geology Section, Seestr. 15, D-18119 Warnemünde, Germany \\ ' Institute of Geological Science, Baltzerstr. 3, University of Bern, CH-3012 Bern, Switzerland
}

\begin{abstract}
In this study, we present first results from an ongoing investigation on the stable barium (Ba) isotope fractionation in the natural barium cycle. Stable Ba isotope signatures of international IAEA reference materials (synthetic barium sulfate, IAEA-SO-5, -6, and barium carbonate, IAEA-CO-9), natural Ba minerals and experimental Ba precipitates have been analyzed as a first approach to evaluate potential discriminating processes in the global geochemical barium cycle. Measurements were carried out on a multi-collector ICP-MS applying a ${ }^{130} \mathrm{Ba} /{ }^{135} \mathrm{Ba}$ double spike. Data are expressed as per mil deviation from a laboratory Ba nitrate standard solution in the $\delta^{137 / 134}$ Ba notation (external $2 \sigma$ stdev $<0.1 \%$ ). Whereas the various synthetic solid standards and a synthetic barium chloride show very similar isotope results close to the nitrate standard solution, the terrestrial barium gangue minerals (four barites, one norsethite $\left[\mathrm{BaMg}\left(\mathrm{CO}_{3}\right)_{2}\right]$ ) were close to, or depleted in the heavy isotope $\left(\delta^{137 / 134} \mathrm{Ba}\right.$ values down to $-0.2 \%$ ), compared to the standard solution. A natural barite from China derived from a mineral collection gave an isotope value of $-0.4 \%$. High $\delta^{34} \mathrm{~S}$ and $\delta^{18} \mathrm{O}$ ratios in this sample point to a formation under influence of microbial sulfate reduction, probably in a marine environment of sedimentary exhalative or diagenetic origin. A value of $\delta^{137 / 134} \mathrm{Ba}=-0.5 \%$ was found in a diagenetic barite sample from ODP Leg 207. The observed natural discriminations are clearly larger than the analytical uncertainty of the stable isotope measurements, indicating significant isotope discrimination in the natural barium cycle. Precipitation experiments from aqueous barium chloride solutions at temperatures of $\sim 21^{\circ} \mathrm{C}$ and $80^{\circ} \mathrm{C}$ indicate that the light Ba isotope is enriched in pure barium carbonate and barium sulfate compared to the aqueous solution. A maximum isotope fractionation of $-0.3 \%$ is observed for both barium carbonate and sulfate, that - in the case of $\mathrm{BaCO}_{3}$ - seems to be influenced by precipitation rate and/or the aqueous speciation, but less by temperature.
\end{abstract}

\section{Introduction}

On the continents, barium $(\mathrm{Ba})$ is liberated upon weathering from feldspars or locally enriched barium minerals, effectively sorbed to clay minerals, and transported in both sorbed or dissolved form to the oceans. Barium gangue minerals are formed from hydrothermal residual solutions or from solutions that leached Ba from silicate rocks (Puchelt, 1967). Detrital sources of Ba from continental runoff, hydrothermal alteration, and diagenetic Ba mobility are hard to constrain with Ba concentrations alone. The riverine and hydrothermal Ba input into to ocean, however, may be heterogeneous in isotopic

* Corresponding authors. Böttcher is to be contacted at Leibniz Institute for Baltic Sea Research, Geochemistry \& Stable Isotope Geochemistry Group, Marine Geology Section, Seestr. 15, D-18119 Warnemünde, Germany. Nägler, Institute of Geological Science, Baltzerstr. 3, University of Bern, CH-3012 Bern, Switzerland.

E-mail addresses: michael.boettcher@io-warnemuende.de (M.E. Böttcher), naegler@geo.unibe.ch (T.F. Nägler).

${ }^{1}$ Present address: Section of Earth and Environmental Sciences, University of Geneva, Rue des Maraîchers 13, CH-1205 Geneva, Switzerland. composition. Continental detrital contributions of $\mathrm{Ba}$ to marine sediments are not easily corrected for due to uncertainties in the estimates of the terrigenous $\mathrm{Ba} / \mathrm{Al}$ ratio (Klump et al., 2000; Reitz et al., 2004). In the modern ocean, dissolved Ba shows a variable concentration and a nutrient-type behavior (Chan et al., 1976). As a nonconservative element, it has a relatively short residence time of $11 \mathrm{kyr}$ (Edmond et al., 1979). Barium concentrations are reduced in the upper waters of the open ocean and enriched in deep waters and areas of nutrient upwelling (e.g., Church, 1979). Therefore, variations in the accumulation rate of barium bound to carbonate and sulfate in marine sediments are thought to be indicative of variations in marine biological productivity through time (e.g., Church, 1979; Paytan and Griffith, 2007). In this context, Ganeshram et al. (2003) studied barite formation in seawater with respect to plankton decay. Ba/Ca ratios of marine carbonates are applied based on the assumption that $\mathrm{Ba}$ is metabolically inert upon incorporation into carbonates, which goes conform with a recent study that showed that the $\mathrm{Ba} / \mathrm{Ca}$ ratio of coccoliths varies linearly with the seawater $\mathrm{Ba} / \mathrm{Ca}$ ratio (Langer et al., 2009). While $\mathrm{Sr}$ and Mg are known to get preferably mobilized during 
diagenetic alteration, $\mathrm{Ba}$ is considered to be a more stable element in sulfate-bearing sediment pore waters being at, or close to, saturation with respect to barite. Diagenetic anoxic mobilization in the zone of sulfate depletion and hydrothermal activity are known to produce relatively high levels of authigenic barium unrelated to biological surface water productivity (Torres et al., 1996). Furthermore, McManus et al. (1998) presented strong evidence that solid-phase Ba preservation may be compromised in the presence of suboxic diagenetic pore fluids.

In the present study, we introduce the fractionation of stable Ba isotopes as a new tool to constrain Ba behavior in the global element cycle. The isotopic composition of Ba was measured as early as 1938 (Nier, 1938). Eugster et al. (1969) improved the precision significantly (sub per mil range). These values were further refined by McCulloch and Wasserburg (1978). Ba isotope fractionation studies of terrestrial samples, however, are still scarce. Eugster et al. (1969) were the first to apply the double spike technique to Ba isotope fractionation measurements. They analyzed six stone meteorites, silicate inclusions of two iron meteorites, terrestrial diabase standard (W-1) and reagent barium. The average meteoritic Ba isotopic composition agreed with the terrestrial samples within less than $1 \%$. Subsequently a large number of studies on Ba isotope anomalies in extraterrestrial material were published (e.g., McCulloch and Wasserburg, 1978; Hidaka et al., 2003; Ranen and Jacobsen, 2006; Andreasen and Sharma, 2007). In addition, Ba from the unique $2 \mathrm{Ga}$-old natural fission reactor of Oklo and Bangombé was analyzed for fissiogenic Ba isotope anomalies (e.g., Hidaka et al., 1993; Hidaka and Gauthier-Lafaye, 2008). The decay of Ba isotopes was investigated in barites (Pujol et al., 2009). However, the path of mass dependent fractionation of stable Ba isotopes was not further followed in terrestrial samples. Besides possible biological interactions, inorganic processes like mineral precipitation, complexation, diffusion and/or sorption-desorption, are processes that potentially may induce mass dependent variations in the Ba isotope composition of aqueous and solid phases. Therefore, besides analyzing different natural Ba minerals, we conducted a first set of experiments to study isotope discrimination occurring during precipitation of pure barium carbonate and sulfate at different temperatures, in order to give a first estimate for isotope fractionation upon diagenetic mineral precipitation. Ba isotopic compositions of various international IAEA standards (both carbonate and sulfate) are also reported for further use in interlaboratory comparison studies.

\section{Material}

\subsection{Standard material}

A barium nitrate $\left(\mathrm{Ba}\left(\mathrm{NO}_{3}\right)_{2}\right)$ ICP-OES standard solution from Fluka Aldrich was used for internal isotope standardization in this study. Three international reference materials from IAEA (Vienna), namely IAEA-SO-5 (batch \# 34) barium sulfate, IAEA-SO-6 (batch \# 34) barium sulfate, and barium carbonate (batch \# 56) IAEA-CO-9 were analyzed in this study. Due to the observed Ba stable isotope homogeneity, which is likely caused by the used Ba salt mother solution upon synthesis, we suggest to use both IAEA barium sulfate and barium carbonates as international Ba isotope standards.

\subsection{Natural samples}

The norsethite sample (NOR 847, $\mathrm{BaMg}\left(\mathrm{CO}_{3}\right)_{2}$; Böttcher et al., 1997) is a mineral from the zinc-lead-copper deposit in Rosh Pinah, Namibia (Steyn and Watson, 1967). The terrestrial barite samples were provided by Deutsche Baryt-Industrie, Bad Lauterberg, via M. Steinkamm except LB GH which is a barite gangue mineral from the valley of Lauterbrunnen, Switzerland. G-SE is a barite gangue mineral from Schlottwitz, Erzgebirge, Germany. G-GH and G-WH are barite gangue minerals from the localities Glücksrad and Wolkenhügel in the Harz
Mountains, Germany, respectively. Chin-1 is a massive white barite from an undisclosed locality in China that was provided by Deutsche Baryt-Industrie, Bad Lauterberg (Steinkamm, M., pers. communication, 2009). Sample DEM-1 is a well-defined clear diagenetic barite $\left(\mathrm{BaSO}_{4}\right)$, recovered from lower part of the core of the Demerara Rise, ODP Leg 207 (Hole 1258A, Core34R, Section 4W). This barite is precipitated from pore waters that are influenced by diffusional transport of the reacting species, induced by the anaerobic oxidation of methane (Arndt et al., 2009; Böttcher and Dietzel, 2010).

\section{Methods}

\subsection{Chemical sample preparation}

$\mathrm{BaCl}_{2} \cdot \mathrm{H}_{2} \mathrm{O}$ was dissolved in deionized water whereas $\mathrm{BaCO}_{3}$ and $\mathrm{BaMg}\left(\mathrm{CO}_{3}\right)_{2}$ were dissolved in distilled $2.5 \mathrm{M} \mathrm{HCl}$. To dissolve $\mathrm{BaSO}_{4}$ samples and standards a method similar to that of Breit et al. (1985) was employed. However, to avoid Ba contamination, no paper filters were used. The grains of the natural barite samples were ground in an agate mortar. About $5 \mathrm{mg}$ of barite powder, $50 \mathrm{mg}$ of $\mathrm{Na}_{2} \mathrm{CO}_{3}$ (anhydrous suprapur, $99.999 \%$ sodium carbonate) and $1 \mathrm{ml}$ of distilled water were added into a Savilex beaker. The mixture was heated for $4 \mathrm{~h}$ on $95^{\circ} \mathrm{C}$. Deionized water was intermittently added to keep the liquid content at approximately $1 \mathrm{ml}$. The newly formed liquid $\mathrm{Na}_{2} \mathrm{SO}_{4}$ (strongly alkaline) was separated from the solid residue $\left(\mathrm{BaCO}_{3}\right)$ using a pipette to decant. However, about $25 \mu \mathrm{l}$ of $\mathrm{Na}_{2} \mathrm{SO}_{4}$ was left behind with the solid residue. Another $50 \mathrm{mg}$ of $\mathrm{Na}_{2} \mathrm{CO}_{3}$, along with $1 \mathrm{ml}$ of deionized water, were added to the residue and the heating procedure was repeated. After decantation, the solid residue was repeatedly diluted with distilled water, which was subsequently decanted by pipette. Finally, the solid residue, along with about $25 \mu$ of distilled water, was dissolved with distilled $2.5 \mathrm{M} \mathrm{HCl}$. Based on semiquantitative optical estimation sample DEM- 1 had a solid residue of roughly $5 \%$ from the original $5 \mathrm{mg} \mathrm{BaSO}$. A second powder aliquot of DEM-1 was processed through chemistry as described above. However, the $\mathrm{Na}_{2} \mathrm{CO}_{3}$-heating step was performed only once. The resulting main solution had a solid residue of roughly $10 \%$. The solid residue of the sample was analyzed by SEM (FEI XL30 Sirion FEG, University of Fribourg). EDS (a lithium doped silicon detector with an S-UTW polymer window) semi-quantitative stoichiometrical analysis revealed the presence of $\mathrm{BaSO}_{4}$ and a C-F phase. Hence, the sample was not completely dissolved. The C-F phase most likely is due to traces of Teflon. The unfractionated results are discussed in Section 4. Residues based on visual estimation were also detected in G-SE ( 8\%), G-GH $(\sim 8 \%)$ and $\mathrm{LB}$ GH $(\sim 10 \%)$. Further residues in other $\mathrm{BaSO}_{4}$ samples/standards are possible but were not discernable due to the small fraction or the milky color of the beaker.

\subsection{Precipitation experiments}

An initial aqueous $5 \% \mathrm{BaCl}_{2}$ solution was prepared from synthetic $\mathrm{BaCl}_{2} \cdot 2 \mathrm{H}_{2} \mathrm{O}$ (pro analysi (p.a.) grade quality, Merck). Precipitation experiments of synthetic $\mathrm{BaCO}_{3}$ were carried out at room temperature (20 to $23{ }^{\circ} \mathrm{C}$, hereafter termed $21^{\circ}$ ) and $80^{\circ} \mathrm{C} .13 \mathrm{ml}$ of a $1 \% \mathrm{NaHCO}_{3}$ solution were slowly added to $100 \mathrm{ml}$ of an aqueous $5 \% \mathrm{BaCl}_{2}$ solution (experiments Ba-BIK, slow precipitation rate). In the Ba-CAR experiments (fast precipitation rate), $10 \mathrm{ml}$ of a $1 \% \mathrm{Na}_{2} \mathrm{CO}_{3}$ solution were slowly added to $100 \mathrm{ml}$ of an aqueous $5 \% \mathrm{BaCl}_{2}$ solution. The solutions were continuously agitated by a magnet stirrer that was also used to heat the experimental solution to $80^{\circ} \mathrm{C}$ in the respective experiments. The $\mathrm{pH}$ in the $21^{\circ} \mathrm{C}$-experiments was measured in a parallel run with an ion-selective electrode (Mettler Toledo InLab Basics electrode with a Schott handylab pH11 pH meter) at the beginning of the experiment and after successive precipitation steps. It was found that the $\mathrm{pH}$ increased from initially 5.5 via 6.9 to a value of 6.2 after one hour (Ba$\mathrm{BIK})$. In experiment Ba-CAR, the $\mathrm{pH}$ increased from an initial value of 
5.6 to 8.0 (immediately after the addition of the sodium carbonate solution) staying constant at 7.5 between 30 and $60 \mathrm{~min}$. Barium sulfate was precipitated from $5 \% \mathrm{BaCl}_{2}$ solutions at $21^{\circ}$ and $80{ }^{\circ} \mathrm{C}$ by the dropwise slow addition of $10 \mathrm{ml}$ of a $1 \% \mathrm{Na}_{2} \mathrm{SO}_{4}$ solution. In these experiments, the initial $\mathrm{BaCl}_{2}$ solution was acidified with $\mathrm{HCl}$ to a $\mathrm{pH}$ below 4 to avoid co-precipitation of $\mathrm{BaCO}_{3}$. The relatively small fractions of precipitated barium carbonate and barium sulfate were chosen to avoid changes in the barium isotopic composition of the mother metal solution due to Rayleigh-type closed system effects (e.g., Hartmann and Nielsen, 1969). $15 \mathrm{~h}$ after the precipitation experiment, the solution was filtered through $0.45 \mu \mathrm{M}$ and the precipitate carefully washed with deionized water and dried at $60{ }^{\circ} \mathrm{C}$ in a drying oven. All chemicals used were of p.a. quality. The calculated total amount of barium precipitated in both experiments was below $5 \%$.

\subsection{Analytical considerations and techniques of $\mathrm{Ba}$ isotopes}

Barium has 7 stable isotopes, which are 130, 132, 134, 135, 136, 137 and 138. Their abundance is $0.1058,0.1012,2.417,6.592,7.853$, 11.232 and $71.699 \%$, respectively (Eugster et al., 1969, Table 1). Ba masses 137 and 134 were selected as natural sample masses and the 130-135 pair was chosen as double spike masses. The four isotopes were selected to suit MC-ICP-MS and also possible TIMS analyses at a later stage. ${ }^{138} \mathrm{Ba}$ was considered not suitable for analysis as it is very abundant $(71.7 \%)$ and, hence, the difference in monitored voltage between the various analyzed isotopes would be inconveniently large. Moreover, there are isobaric interferences of La and Ce on ${ }^{138} \mathrm{Ba}$; Ce further interferes on ${ }^{136} \mathrm{Ba}$ (Table 1). ${ }^{137} \mathrm{Ba}$ was chosen as reference because it is the second most abundant in nature and the most abundant $\mathrm{Ba}$ isotope monitored. Generally, ${ }^{132} \mathrm{Ba}$ and ${ }^{136} \mathrm{Ba}$ are not reported due to larger contributions from the spike and isobaric interferences $\left({ }^{132} \mathrm{Xe}\right.$ and $\left.{ }^{136} \mathrm{Ce}\right)$; however, ${ }^{132} \mathrm{Ba}$ data are given for pure standard measurements (Table 2) (see below). A spike mixture was prepared that would allow $90 \% / 10 \%$ spike versus analyte enrichment on the selected 130-135 spike masses.

Interfering elements on the measured $\mathrm{Ba}$ isotopes are $\mathrm{Xe}$ and $\mathrm{Te}$ (Table 1). Isobaric Xe interferences on MC-ICP-MS are possible from impurities of the Ar plasma. There is no interfering mass on ${ }^{129} \mathrm{Xe}$ and ${ }^{131} \mathrm{Xe}$; therefore these masses were selected to monitor xenon interferences on barium. In the case of ${ }^{131} \mathrm{Xe}$ exceeding $0.2 \mathrm{mV}$ the program calculations were set such that a Xe correction was applied to the barium masses 130,132 and 134 . Generally, relative ${ }^{130} \mathrm{Xe}$ interferences on ${ }^{130} \mathrm{Ba}$ were smaller than $0.06 \%$. For unspiked measurements ${ }^{130} \mathrm{Xe}$ interferences occasionally reached up to $0.3 \%$. Even for these samples the reproducibility of the ${ }^{130} \mathrm{Ba} /{ }^{135} \mathrm{Ba}$ ratio was $0.01 \%$, indicating that the Xe correction is sufficiently precise (Table 2). Tellurium can cause isobaric interferences on ${ }^{130} \mathrm{Ba}$. The very low concentrations of Te in deep seawater $(0.02-0.05 \mathrm{ppt}$; Li, 1991 ) and continental crust (5 ppb; Wedepohl, 1995) in comparison to the much higher Ba concentrations of 15000 ppt for deep seawater (Li, 1991) and 250-576 ppm for continental crust (Rudnick and Fountain, 1995; Rudnick and Gao, 2004) do not suggest significant
Table 2

Isotopic composition of $\mathrm{Ba}$ (isotopes applied in this study). Average Ba isotope ratios from multiple unspiked measurements, compared to the respective data from Eugster et al. (1969). Note that ${ }^{130} \mathrm{Ba} /{ }^{135} \mathrm{Ba}$ and ${ }^{132} \mathrm{Ba} /{ }^{135} \mathrm{Ba}$ of this study have larger uncertainties than ${ }^{134} \mathrm{Ba} /{ }^{135} \mathrm{Ba}$ due to low abundance and Xe interference. For ${ }^{130} \mathrm{Ba} /{ }^{135} \mathrm{Ba}$ these influences are significantly reduced in spiked measurements due to the addition of ${ }^{130} \mathrm{Ba}$ from the spike. ${ }^{132} \mathrm{Ba} /{ }^{135} \mathrm{Ba}$ is not used for geological interpretations. ${ }^{1} \mathrm{n}=5$. ${ }^{2} \mathrm{All}$ data were (re)normalized to ${ }^{137} \mathrm{Ba} /{ }^{135} \mathrm{~B}=1.73083$.

\begin{tabular}{lllll}
\hline & Eugster et al. & $2 \sigma$ std.err. (\%) & This study & $2 \sigma$ std.err. $(\%)^{1}$ \\
\hline${ }^{137} \mathrm{Ba} /{ }^{135} \mathrm{Ba}^{2}$ & 1.70383 & & 1.70383 & \\
${ }^{134} \mathrm{Ba} /{ }^{135} \mathrm{Ba}$ & 0.36665 & 0.06 & 0.366678 & 0.002 \\
${ }^{132} \mathrm{Ba} /{ }^{135} \mathrm{Ba}$ & 0.01536 & 0.09 & 0.015362 & 0.022 \\
${ }^{130} \mathrm{Ba} /{ }^{135} \mathrm{Ba}$ & 0.01605 & 0.09 & 0.016048 & 0.011 \\
\hline
\end{tabular}

isobaric interferences from Te on ${ }^{130} \mathrm{Ba}$ for the samples analyzed here. $\mathrm{The} \mathrm{Ba}$ /Te ratio of deep seawater is about 300000 to 750000 and for continental crust approximately 50000 to 115000 . Furthermore, Te is mainly present as $\mathrm{Te}^{4+}$ and $\mathrm{Te}^{6+}$ in seawater. The small ionic radius of $\mathrm{Te}^{4+}$ and $\mathrm{Te}^{6+}$ does not make it a suitable candidate to substitute for $\mathrm{Ba}$ in the barite crystal lattice. To the extent that tellurate substitutes for sulfate in $\mathrm{BaSO}_{4}$, it will also be discriminated against $\mathrm{Ba}$ together with sulfate in the dissolution process via $\mathrm{BaCO}_{3}$ formation. To validate these considerations mass 128 ( Te and Xe) was monitored by ion counting. After the Xe interference correction no detectable signal remained.

\subsection{Standard and double spike calibration}

Theoretical spike-sample mixtures were simulated in a lower hemisphere Excel calculation spreadsheet. These calculations allow simulating the angles between the pure standard fractionation trendline, the pure 130-135 spike fractionation trendline, and the spike-standard mixing line. Different spike compositions and sample-spike mixtures can be tested in the spreadsheet. Highest measurement precisions can be achieved at 130-135 spike mixtures and spike-sample mixtures where all three above-mentioned trendlines cross with high angles. If the trendlines cross at low angles the intersection is not well-defined which leads to a low precision.

The double spike was prepared from ${ }^{130} \mathrm{Ba}$ (from carbonate) and ${ }^{135} \mathrm{Ba}$ (from nitrate), (Oak Ridge National Laboratory; enrichment 37.6 and $93.4 \%$, respectively). As a first approach pure standard and pure spike composition were determined from multiple measurements. Normalized standard ratios were then compared with data from Eugster et al. (1969) (Table 2) to ensure that no anomalies, apart from instrumental fractionation, are present within analytical error. In a next step pure standard and pure spike solutions were doped with a pure Nd standard of known isotopic composition. The instrumental fractionation correction was determined on the basis of the measured ${ }^{142} \mathrm{Nd} /{ }^{144} \mathrm{Nd}$ ratio of the $\mathrm{Nd}$ standard and then applied to correct the ${ }^{137} \mathrm{Ba} /{ }^{135} \mathrm{Ba}$ ratio of the pure standard and pure spike. The latter ratio was chosen to fit the collector spacing and mass range in combination with the Nd masses, and to avoid interferences. Subsequently, the calibration was verified by measuring different spike/standard

Table 1

Barium isotopes and interfering elements. Detected relative ${ }^{130}$ Xe interferences on ${ }^{130}$ Ba were smaller than $0.06 \% .{ }^{1}$ Rounded after Parrington et al. (1996). ${ }^{2}$ Percent of respective element. ${ }^{3}$ Eugster et al. (1969).

\begin{tabular}{|c|c|c|c|c|c|c|c|c|c|c|}
\hline Ba mass & 128 & 129 & 130 & 131 & 132 & 134 & 135 & 136 & 137 & 138 \\
\hline Atomic mass ${ }^{1}$ & & - & 129.906 & - & 131.905 & 133.905 & 134.906 & 135.905 & 136.906 & 137.905 \\
\hline Abundance $(\%)^{2,3}$ & & - & 0.1058 & - & 0.1012 & 2.417 & 6.592 & 7.853 & 11.232 & 71.699 \\
\hline Selected spike masses: & & & $\mathrm{X}$ & & & & $\mathrm{X}$ & & & \\
\hline $\begin{array}{l}\text { Monitored masses: } \\
\text { Interfering elements (\%) }{ }^{2,1}\end{array}$ & & & & & & $\mathrm{X}$ & & & $\mathrm{X}$ & \\
\hline $\mathrm{Xe}$ & 1.92 & 26.4 & 4.1 & 21.2 & 26.9 & 10.4 & & 8.9 & & \\
\hline $\mathrm{Ce}$ & & & & & & & & 0.19 & & 0.25 \\
\hline $\mathrm{La}$ & & & & & & & & & & 0.09 \\
\hline $\mathrm{Te}$ & 31.8 & & 34.5 & & & & & & & \\
\hline
\end{tabular}


mixtures. Finally, the range of accurately measured spike/standard ${ }^{130} \mathrm{Ba} /{ }^{137} \mathrm{Ba}$ ratio was empirically defined to be between 0.1 and 0.43 . Barium isotopes are given as $\delta{ }^{137 / 134} \mathrm{Ba}=\left(\left({ }^{137} \mathrm{Ba} /{ }^{134} \mathrm{Ba}\right)_{\text {sample }} /\left({ }^{137} \mathrm{Ba} /\right.\right.$ $\left.\left.{ }^{134} \mathrm{Ba}\right)_{\text {standard }}-1\right) * 1000$ relative to the $\mathrm{Ba}\left(\mathrm{NO}_{3}\right)_{2}$-standard solution.

Table 3

Barium standard long-term record. The $2 \sigma$ standard deviation of the long-term standard evolution over 10 months is $\pm 0.15 \%$. The spike-standard mixture ratio was monitored as 130/137-ratio (only corrected for instrumental mass bias).

\begin{tabular}{|c|c|c|c|c|c|}
\hline Date & Run number & $\delta^{137 / 134} \mathrm{Ba}$ & $2 \sigma \mathrm{sd}$ & $130 / 137$ & Cycles \\
\hline 05/04/2009 & 15123 & 0.00 & 0.02 & 0.17 & $35 / 40$ \\
\hline $05 / 04 / 2009$ & 15126 & 0.00 & 0.03 & 0.17 & $36 / 40$ \\
\hline 05/04/2009 & 15130 & 0.02 & 0.02 & 0.17 & $39 / 40$ \\
\hline 05/04/2009 & 15134 & 0.01 & 0.02 & 0.17 & $37 / 40$ \\
\hline 05/04/2009 & Average & 0.01 & & & \\
\hline $05 / 04 / 2009$ & $2 \sigma \mathrm{sd}$ & 0.02 & & & \\
\hline 07/20/2009 & 15441 & 0.00 & 0.03 & 0.16 & $37 / 40$ \\
\hline $07 / 20 / 2009$ & 15442 & -0.07 & 0.02 & 0.16 & $36 / 40$ \\
\hline 07/20/2009 & 15443 & 0.01 & 0.03 & 0.16 & $38 / 40$ \\
\hline $07 / 20 / 2009$ & 15445 & 0.00 & 0.02 & 0.16 & $37 / 40$ \\
\hline 07/20/2009 & 15449 & 0.00 & 0.03 & 0.16 & $37 / 40$ \\
\hline $07 / 20 / 2009$ & 15453 & -0.09 & 0.02 & 0.16 & $35 / 40$ \\
\hline $07 / 20 / 2009$ & Average & -0.02 & & & \\
\hline $07 / 20 / 2009$ & $20 \mathrm{sd}$ & 0.09 & & & \\
\hline $07 / 21 / 2009$ & 15455 & -0.03 & 0.03 & 0.18 & $38 / 40$ \\
\hline $07 / 21 / 2009$ & 15456 & -0.04 & 0.02 & 0.18 & $38 / 40$ \\
\hline $07 / 21 / 2009$ & 15460 & -0.07 & 0.02 & 0.18 & $36 / 40$ \\
\hline $07 / 21 / 2009$ & 15464 & -0.13 & 0.02 & 0.18 & $34 / 40$ \\
\hline $07 / 21 / 2009$ & 15465 & -0.02 & 0.02 & 0.18 & $36 / 40$ \\
\hline $07 / 21 / 2009$ & 15466 & -0.05 & 0.02 & 0.18 & $36 / 40$ \\
\hline $07 / 21 / 2009$ & 15467 & -0.05 & 0.02 & 0.18 & $34 / 40$ \\
\hline $07 / 21 / 2009$ & 15470 & -0.07 & 0.02 & 0.18 & $37 / 40$ \\
\hline $07 / 21 / 2009$ & Average & -0.06 & & & \\
\hline $07 / 21 / 2009$ & $2 \sigma s d$ & 0.07 & & & \\
\hline $07 / 22 / 2009$ & 15471 & -0.05 & 0.02 & 0.18 & $35 / 40$ \\
\hline $07 / 22 / 2009$ & 15472 & -0.04 & 0.04 & 0.18 & $36 / 40$ \\
\hline $07 / 22 / 2009$ & 15477 & -0.04 & 0.03 & 0.18 & $39 / 40$ \\
\hline $07 / 22 / 2009$ & 15478 & -0.10 & 0.03 & 0.18 & $39 / 40$ \\
\hline $07 / 22 / 2009$ & 15479 & -0.17 & 0.02 & 0.18 & $36 / 40$ \\
\hline $07 / 22 / 2009$ & 15480 & -0.19 & 0.02 & 0.18 & $39 / 40$ \\
\hline $07 / 22 / 2009$ & 15485 & -0.04 & 0.03 & 0.18 & $35 / 40$ \\
\hline $07 / 22 / 2009$ & 15488 & -0.20 & 0.03 & 0.18 & \\
\hline $07 / 22 / 2009$ & Average & -0.10 & & & \\
\hline $07 / 22 / 2009$ & $2 \sigma s d$ & 0.14 & & & \\
\hline $10 / 29 / 2009$ & 15947 & 0.10 & 0.02 & 0.18 & $38 / 40$ \\
\hline $10 / 29 / 2009$ & 15952 & 0.12 & 0.03 & 0.18 & $37 / 40$ \\
\hline $10 / 29 / 2009$ & Average & 0.11 & & & \\
\hline $10 / 29 / 2009$ & $2 \sigma s d$ & 0.03 & & & \\
\hline $10 / 30 / 2009$ & 15955 & 0.12 & 0.03 & 0.18 & $36 / 40$ \\
\hline $10 / 30 / 2009$ & 15956 & 0.11 & 0.02 & 0.18 & $38 / 40$ \\
\hline $10 / 30 / 2009$ & 15957 & 0.09 & 0.02 & 0.18 & $36 / 40$ \\
\hline $10 / 30 / 2009$ & 15958 & 0.10 & 0.02 & 0.18 & $39 / 40$ \\
\hline $10 / 30 / 2009$ & 15967 & 0.09 & 0.03 & 0.18 & $35 / 40$ \\
\hline $10 / 30 / 2009$ & 15972 & 0.10 & 0.03 & 0.18 & $38 / 40$ \\
\hline $10 / 30 / 2009$ & 15977 & 0.06 & 0.02 & 0.18 & $38 / 40$ \\
\hline $10 / 30 / 2009$ & Average & 0.09 & & & \\
\hline $10 / 30 / 2009$ & $2 \sigma s d$ & 0.04 & & & \\
\hline $11 / 05 / 2009$ & 15997 & 0.03 & 0.02 & 0.18 & $36 / 40$ \\
\hline $11 / 05 / 2009$ & 15998 & 0.00 & 0.03 & 0.18 & $35 / 40$ \\
\hline $11 / 05 / 2009$ & 15999 & 0.06 & 0.03 & 0.18 & $37 / 40$ \\
\hline $11 / 05 / 2009$ & 16000 & 0.09 & 0.03 & 0.18 & $39 / 40$ \\
\hline $11 / 05 / 2009$ & 16001 & 0.02 & 0.03 & 0.18 & $36 / 40$ \\
\hline $11 / 05 / 2009$ & 16005 & -0.01 & 0.03 & 0.18 & $39 / 40$ \\
\hline $11 / 05 / 2009$ & 16009 & 0.08 & 0.03 & 0.18 & $33 / 40$ \\
\hline $11 / 05 / 2009$ & 16013 & 0.07 & 0.03 & 0.18 & $38 / 40$ \\
\hline $11 / 05 / 2009$ & 16018 & 0.00 & 0.02 & 0.18 & $36 / 40$ \\
\hline $11 / 05 / 2009$ & Average & 0.04 & & & \\
\hline $11 / 05 / 2009$ & $2 \sigma s d$ & 0.08 & & & \\
\hline $11 / 06 / 2009$ & 16019 & 0.06 & 0.03 & 0.18 & $38 / 40$ \\
\hline $11 / 06 / 2009$ & 16020 & 0.08 & 0.03 & 0.18 & $36 / 40$ \\
\hline $11 / 06 / 2009$ & 16021 & 0.02 & 0.04 & 0.18 & $35 / 40$ \\
\hline $11 / 06 / 2009$ & 16025 & 0.04 & 0.02 & 0.18 & $35 / 40$ \\
\hline $11 / 06 / 2009$ & 16029 & 0.02 & 0.03 & 0.18 & $34 / 40$ \\
\hline $11 / 06 / 2009$ & 16034 & 0.05 & 0.02 & 0.18 & $38 / 40$ \\
\hline $11 / 06 / 2009$ & Average & 0.05 & & & \\
\hline $11 / 06 / 2009$ & $2 \sigma s d$ & 0.05 & & & \\
\hline
\end{tabular}

Table 3 (continued)

\begin{tabular}{llclll}
\hline Date & Run number & $\delta^{137 / 134} \mathrm{Ba}$ & $2 \sigma \mathrm{sd}$ & $130 / 137$ & Cycles \\
\hline $02 / 24 / 2010$ & 16378 & -0.07 & 0.02 & 0.18 & $36 / 40$ \\
$02 / 24 / 2010$ & 16379 & 0.03 & 0.03 & 0.16 & $38 / 40$ \\
$02 / 24 / 2010$ & 16380 & -0.09 & 0.03 & 0.16 & $37 / 40$ \\
$02 / 24 / 2010$ & 16384 & -0.02 & 0.03 & 0.16 & $39 / 40$ \\
$02 / 24 / 2010$ & 16388 & -0.03 & 0.02 & 0.16 & $37 / 40$ \\
$02 / 24 / 2010$ & Average & -0.03 & & & \\
$02 / 24 / 2010$ & 2o sd & 0.09 & & & \\
& Average all data & 0.00 & & & \\
& 2o sd all data & 0.15 & & & \\
& & & &
\end{tabular}

\subsection{Data acquisition and reduction}

Measurements were performed on a double focusing Nu instruments ${ }^{\circledR}$ multi-collector ICP-MS equipped with 12 fixed Faraday cups (and 3 ion counters) in static mode. Before analyses the plasma was run for at least $2 \mathrm{~h}$ to achieve stable measurement conditions. ${ }^{131} \mathrm{Ba}$ was set to be collected in the axial cup. Data acquisition generally comprised 4 blocks of 10 cycles per measurement. Peak centering was performed after each block.

Standard and sample solutions were mixed with the spike and diluted with $0.5 \mathrm{M} \mathrm{HNO}_{3}$ to achieve a final natural ${ }^{137} \mathrm{Ba}$ concentration between approximately 0.025 and $0.030 \mathrm{ppm}$. Measurements consume about $1 \mathrm{ml}$ of the solution, thus the ${ }^{137} \mathrm{Ba}$ amount needed is about $25 \mathrm{ng}$, or $230 \mathrm{ng}$ of total Ba. Samples were ingested with a Teflon PFA micromist ${ }^{\circledR}$ ESI nebulizer and transferred into the ICP-MS through an ESI®Apex-Q desolvating high sensitivity Inlet system. After each measurement the system was cleaned by running $0.5 \mathrm{M} \mathrm{HNO}_{3}$ for about $10 \mathrm{~min}$. The background was acquired by deflection of the electrostatic analyzer (ESA). Generally, the internal standard was measured after three to four sample analyses. The barium blank was constantly $<0.04 \mathrm{ng}$. The intensities of the spike/standard and spike/ sample mixtures yielded on average around $1,8,0.24$ and $0.2 \mathrm{~V}$ for barium masses 137, 135, 134 and 130, respectively. Intensities approaching $0.1 \mathrm{~V}$ were avoided as this leads to a magnification of the internal error. The spike-standard mixture ratio was monitored as ${ }^{130} \mathrm{Ba} /{ }^{137} \mathrm{Ba}$-ratio.

The three-dimensional data reduction procedure of Siebert et al. (2001) was applied. It is very similar to procedures of Hofmann (1971) and Johnson and Beard (1999). Thereby, the exponential fractionation law is applied for instrumental and natural mass dependent fractionation.

\subsection{Sulfur and oxygen isotope measurements}

Sulfur and oxygen isotope measurements of sample Chin-1 were carried out using a Thermo Electron Finnigan MAT 253 gas mass spectrometer connected to a Thermo Finnigan Flash elemental analyzer or a Finnigan TC/EA via a Thermo Electron Conflo-IV interface at IOW. Stable isotope ratios of DEM- 1 were measured on a Thermo Finnigan Delta ${ }^{+}$connected to a Eurovector elemental analyzer (EA) via a Thermo Finnigan Conflo-III interface (at MPI-MM, Bremen). For sulfur isotope measurements international standards (IAEA-S-1, -3, SO-5, SO-6, NBS-127), and for oxygen isotope measurements, IAEASO-5 and -SO-6, as well as further IAEA standards and internal reference materials were used for calibration. Stable sulfur and oxygen isotope ratios are given in the conventional $\delta$-notation via the V-CDT and V-SMOW standards, respectively.

\section{Results and discussion}

The long-term $2 \sigma$ standard reproducibility of the Ba isotopes over a period of about 10 months was $\pm 0.15 \%$ o $(n=55$, Table 3, Fig. 1$)$. Samples were corrected relative to daily averages. Daily $2 \sigma$ standard deviation values range from \pm 0.02 to $\pm 0.14 \%$.The ${ }^{130} \mathrm{Ba} /{ }^{137} \mathrm{Ba}$ spike/ 


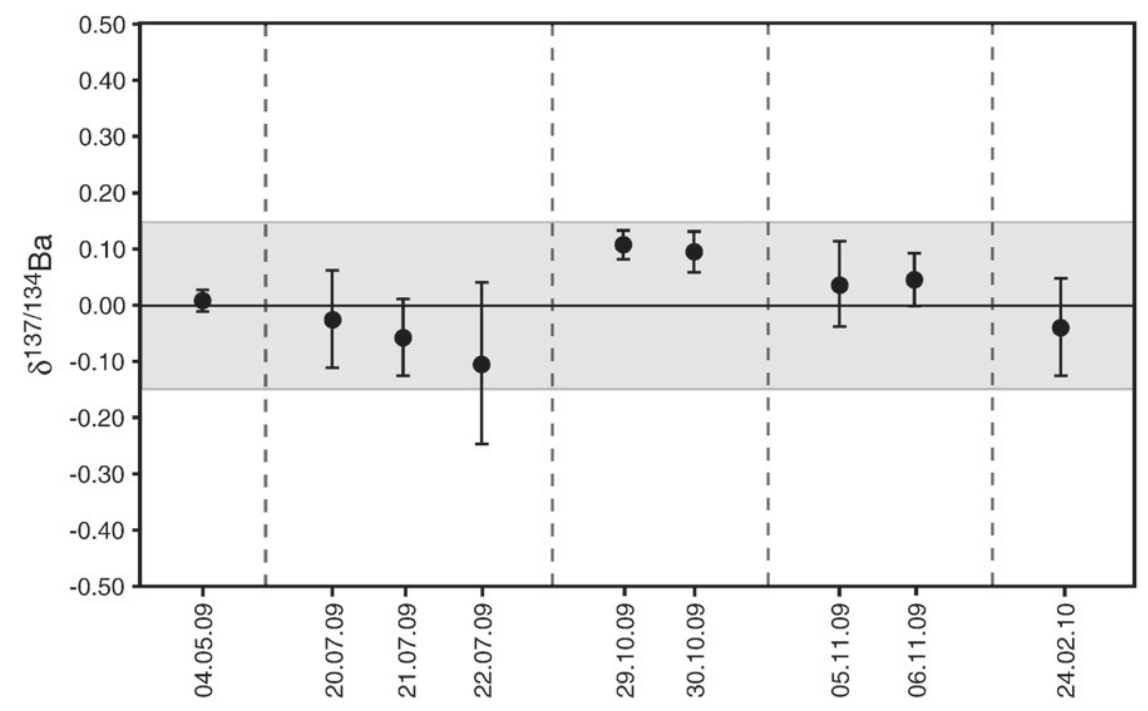

Fig. 1. Daily $2 \sigma$ standard deviation values range from \pm 0.02 to $\pm 0.14 \%$ o (see also Table 3 ). The long-term $2 \sigma$ standard deviation of the internal standard over a period of 10 months is $\pm 0.15 \%$ (grey shaded area, $n=55$ ). Samples are corrected for the long time drift based on the daily mean. The x-axis is not to scale.

standard-ratio based on intensity is given as $130 / 137$ in Tables 3 and 4. The DEM-1 aliquot that underwent the $\mathrm{Na}_{2} \mathrm{CO}_{3}$ treatment only once has a ${ }^{130} \mathrm{Ba} /{ }^{137} \mathrm{Ba}$ ratio of 0.32 opposed to 0.24 of the aliquot that was subject to this chemical step twice, even though the prepared spike to dissolved sample ratio was similar. However, weighing sample amounts of a few mg into Teflon beakers is prone to significant electrostatic problems. The observed ${ }^{130} \mathrm{Ba} /{ }^{137} \mathrm{Ba}$ ratios indicate that roughly $30 \%$ less $\mathrm{BaSO}_{4}$ was dissolved from the aliquot that went only once through the $\mathrm{Na}_{2} \mathrm{CO}_{3}$ treatment. The two aliquots produced average $\delta{ }^{137 / 134} \mathrm{Ba}$ values of -0.51 and $-0.49 \%$, respectively. Consequently, the difference in dissolution does not affect the isotopic ratios (Table 4). Possible effects of partial sample dissolution on $\delta^{137}$ ${ }^{134} \mathrm{Ba}$ were further investigated on powdered aliquots from the $\mathrm{BaSO}_{4}$ IAEA-SO-5 standard by using lower amounts of $\mathrm{Na}_{2} \mathrm{CO}_{3}$ during chemical procedures. The partial dissolution of $\mathrm{BaSO}_{4}$ of approximately $30,15,10 \%$ yielded a $\delta^{137 / 134} \mathrm{Ba}$ of $0.03 \pm 0.02,0.06 \pm 0.02$ and $0.05 \% \pm 0.04(2 \sigma \mathrm{sd})$. These results compare well with the average of $0.02 \% \pm 0.02$ (2SEM) of the IAEA-SO-5 standard aliquot (Table 4 ) that underwent regular chemistry procedures. Thus, these experiments demonstrate, that potential partial dissolution during chemistry does not significantly affect the barium isotopic composition if at least $10 \%$ of the total aliquot was dissolved. There is further no resolvable offset between sample aliquots that underwent a chemical $\mathrm{H}_{2} \mathrm{O}_{2} / \mathrm{HNO}_{3}$ treatment to remove possible interfering organic matter and aliquots that were not subject to this treatment (Hippler et al., 2004) (Table 4). All standard materials, i.e., all three IAEA standards $\left(\mathrm{BaSO}_{4}\right.$ and $\left.\mathrm{BaCO}_{3}\right)$ and the in-house $\mathrm{Ba}\left(\mathrm{NO}_{3}\right)_{2}$ standard solution, and the synthetic $\mathrm{BaCl}_{2} \cdot 2 \mathrm{H}_{2} \mathrm{O}$ used in the precipitation experiments gave results within a very close range of $0.06 \%$ (Fig. 2 , Table 4 ). This may indicate a similar isotopic composition of the barium source used in the industrial synthesis of the Ba salt and Ba nitrate solution as well as the IAEA Ba sulfate and carbonate preparation.

The different terrestrial $\mathrm{Ba}$ sulfate and $\mathrm{BaMg}$ carbonate gangue samples range from -0.02 to $-0.17 \%$ o (Fig. 2, Table 4). A natural barite, from an undisclosed Chinese locality, gave an isotope value of $-0.4 \%$. Considering the heavy values of $\delta^{34} \mathrm{~S}(+36.4 \%$ vs. V-CDT $)$ and $\delta^{18} \mathrm{O}(+17.4 \%$ vs. V-SMOW $)$ in this sample the barite has been formed in a marine environment from sulfate that was modified by microbial sulfate reduction, probably under sedimentary exhalative or diagenetic conditions (Böttcher et al., 1998; Wortmann et al., 2007; Johnson et al., 2009). This relationship is further supported by the measurement of the diagenetic barite sample (DEM-1; $\delta^{34} \mathrm{~S}=$ $+54.4 \%$, $\delta^{18} \mathrm{O}=+23.4 \%$ ) from ODP Leg 207 , with a $\delta^{137 / 134} \mathrm{Ba}$ of
$-0.5 \%$ (Fig. 2, Table 4). Not considering the Chinese sample, the terrestrial minerals, tentatively used here as a substitute for continental input into seawater, appear to be more or less homogeneous with respect to barium isotope composition, with a maximum range of $0.15 \%$ (Fig. 2, Table 4). This includes barium sulfates as well as the norsethite sample. The Ba isotopic composition of the investigated diagenetic barite sample is isotopically lighter than the gangue minerals. The diagenetic barite is precipitated from marine interstitial waters in counter-diffusional gradients of dissolved barium and sulfate (Torres et al., 1996). Therefore, Ba isotope discrimination could result from processes such as ion diffusion, sorption/desorption processes, and/or incomplete precipitation of the sulfate from the aqueous solution.

We investigated in a first approach Ba isotope discrimination upon precipitation of pure $\mathrm{BaCO}_{3}$ and $\mathrm{BaSO}_{4}$ from aqueous solutions at $21^{\circ}$ and $80{ }^{\circ} \mathrm{C}$ ( $1 \mathrm{~atm}$ total pressure). It was found that the heavy $\mathrm{Ba}$ isotope is generally depleted in the carbonate and sulfate solids down to $-0.3 \%$ o (Fig. 2, Table 4 ). No reservoir effect is expected in the performed experiments, since only a few \% of the total dissolved barium concentration was precipitated. The magnitude of isotope discrimination seems independent of temperature (Fig. 2), but differences are observed between $\mathrm{BaCO}_{3}$ that is formed upon addition of aqueous solutions of $\mathrm{NaHCO}_{3}$ or $\mathrm{Na}_{2} \mathrm{CO}_{3}$. Addition of the latter led to higher $\mathrm{pH}$ values (see above) and a spontaneous ("fast") precipitation of the solid (Ba-CAR). This experiment (Ba-CAR) showed a maximum fractionation of $-0.13 \%$ o compared to the $\mathrm{BaCl}_{2}$-solution.

The addition of sodium bicarbonate $\left(\mathrm{NaHCO}_{3}\right)$ led to smaller $\mathrm{pH}$ shift, corresponding lower thermodynamic supersaturation, and resulting lower precipitation rate upon barium carbonate formation. This resulted in enhanced isotope discrimination, independent of temperature in the Ba-BIC experiments (Fig. 2). Thus, in the Ba-BIC experiments the metal isotopes are more fractionated between solution and solid than in the Ba-CAR experiments with a maximum of $-0.31 \%$ (Fig. 2, Table 4). A similar value was found in the barite synthesis experiments (Fig. 2, Table 4), which took place at high precipitation rate. Hence, an even higher fractionation at lower precipitation rate can be expected. This clearly shows that Ba isotopes are fractionated during solid precipitation and that the magnitude is not constant. Besides precipitation rate, also the aqueous speciation of barium may influence isotope discrimination. The divalent Ba cation is hydrated and may also form ion pairs with the bicarbonate and carbonate ion. Therefore, the difference in $\mathrm{pH}$, as observed in experiments Ba-CAR and Ba-BIC, may have been influenced by the 
Table 4

Results were normalized to the daily average standard value. The ${ }^{130} \mathrm{Ba} /{ }^{137} \mathrm{Ba}$ column reflects the spike/sample mixture as measured, only corrected for instrumental mass bias. *Marks aliquots that underwent a $\mathrm{H}_{2} \mathrm{O}_{2} / \mathrm{HNO}_{3}$ cleaning step to remove organics (Hippler et al., 2004). The 2 SEM is based on repeated measurements.

\begin{tabular}{|c|c|c|c|c|c|c|c|c|c|}
\hline Mineralogy & Sample description & Provenance & Sample name & $\delta^{137 / 134} \mathrm{Ba}$ & $\begin{array}{l}2 \sigma \text { int. } \\
\text { error }\end{array}$ & 2SEM & $\begin{array}{l}2 \sigma \\
\text { ext. sd }\end{array}$ & $130 / 137$ & Cycles \\
\hline & & & IAEA-SO-5 & -0.01 & 0.03 & & 0.09 & 0.21 & $38 / 40$ \\
\hline & & & IAEA-SO-5 & 0.00 & 0.03 & & 0.07 & 0.21 & $38 / 40$ \\
\hline & & & IAEA-SO-5 & 0.03 & 0.03 & & 0.14 & 0.21 & $35 / 40$ \\
\hline & & & IAEA-SO-5 & 0.02 & 0.02 & & 0.05 & 0.22 & $39 / 40$ \\
\hline & & & IAEA-SO-5 & 0.05 & 0.03 & & 0.05 & 0.22 & $35 / 40$ \\
\hline \multirow[t]{5}{*}{$\mathrm{BaSO}_{4}$} & Standard & IAEA & Average IAEA-SO-5 & 0.02 & & 0.02 & & & \\
\hline & & & IAEA-SO-6 & -0.03 & 0.03 & & 0.07 & 0.22 & $35 / 40$ \\
\hline & & & IAEA-SO-6 & -0.07 & 0.03 & & 0.07 & 0.22 & $35 / 40$ \\
\hline & & & IAEA-SO-6 & -0.02 & 0.03 & & 0.04 & 0.23 & $38 / 40$ \\
\hline & & & IAEA-SO-6 & -0.01 & 0.03 & & 0.04 & 0.23 & $38 / 40$ \\
\hline \multirow{5}{*}{$\mathrm{BaSO}_{4}$} & Standard & IAEA & Average IAEA-SO-6 & -0.04 & & 0.03 & & & \\
\hline & & & IAEA-CO-9 & -0.06 & 0.03 & & 0.07 & 0.19 & $35 / 40$ \\
\hline & & & IAEA-CO-9 & 0.00 & 0.03 & & 0.07 & 0.19 & $35 / 40$ \\
\hline & & & IAEA-CO-9 & 0.00 & 0.03 & & 0.14 & 0.19 & $39 / 40$ \\
\hline & & & IAEA-CO-9 & -0.04 & 0.03 & & 0.03 & 0.17 & $37 / 40$ \\
\hline \multirow[t]{3}{*}{$\mathrm{BaCO}_{3}$} & Standard, witherite & IAEA & Average IAEA-CO-9 & -0.03 & & 0.03 & & & \\
\hline & & & $\mathrm{BaCl} 2$ & -0.01 & 0.03 & & 0.03 & 0.16 & \\
\hline & & & $\mathrm{BaCl} 2$ & -0.01 & 0.02 & & 0.04 & 0.16 & $39 / 40$ \\
\hline \multirow{5}{*}{$\mathrm{BaCl}_{2}$} & Educt salt & Experimental & Average $\mathrm{BaCl} 2$ & -0.01 & & 0.01 & & & \\
\hline & & & BaCO3-20-CAR & -0.05 & 0.02 & & 0.03 & 0.15 & $36 / 40$ \\
\hline & & & BaCO3-20-CAR & -0.10 & 0.02 & & 0.04 & 0.15 & $39 / 40$ \\
\hline & & & BaCO3-20-CAR & -0.02 & 0.02 & & 0.05 & 0.14 & $39 / 40$ \\
\hline & & & BaCO3-20-CAR & -0.07 & 0.03 & & 0.05 & 0.14 & $36 / 40$ \\
\hline \multirow[t]{3}{*}{$\mathrm{BaCO}_{3}$} & "Fast" at $21^{\circ} \mathrm{C}$ & Experimental precipitate & Average $\mathrm{BaCO} 3-20-\mathrm{CAR}$ & -0.06 & & 0.04 & & & \\
\hline & & & BaCO3-80-CAR & -0.17 & 0.04 & & 0.04 & 0.13 & $36 / 40$ \\
\hline & & & BaCO3-80-CAR & -0.11 & 0.02 & & 0.05 & 0.12 & $36 / 40$ \\
\hline \multirow[t]{5}{*}{$\mathrm{BaCO}_{3}$} & "Fast" at $80^{\circ} \mathrm{C}$ & Experimental precipitate & Average BaCO3-80-CAR & -0.14 & & 0.07 & & & \\
\hline & & & BaCO3-20-BIK & -0.30 & 0.03 & & 0.09 & 0.20 & $35 / 40$ \\
\hline & & & BaCO3-20-BIK & -0.44 & 0.04 & & 0.04 & 0.22 & $35 / 40$ \\
\hline & & & BaCO3-20-BIK & -0.25 & 0.02 & & 0.05 & 0.20 & $37 / 40$ \\
\hline & & & ВaCO3-20-BIK & -0.28 & 0.03 & & 0.05 & 0.20 & $38 / 40$ \\
\hline \multirow[t]{4}{*}{$\mathrm{BaCO}_{3}$} & "Slow" at $21^{\circ} \mathrm{C}$ & Experimental precipitate & Average BaCO3-20-BIK & -0.32 & & 0.07 & & & \\
\hline & & & BaCO3-80-BIK & -0.28 & 0.03 & & 0.03 & 0.28 & $38 / 40$ \\
\hline & & & $\mathrm{BaCO}-80-\mathrm{BIK}$ & -0.28 & 0.02 & & 0.04 & 0.18 & $37 / 40$ \\
\hline & & & BaCO3-80-BIK & -0.27 & 0.02 & & 0.05 & 0.16 & $37 / 40$ \\
\hline \multirow[t]{3}{*}{$\mathrm{BaCO}_{3}$} & "Slow" at $80^{\circ} \mathrm{C}$ & Experimental precipitate & Average BaCO3-80-BIK & -0.28 & & 0.01 & & & \\
\hline & & & BaSO4-20 & -0.25 & 0.04 & & 0.04 & 0.29 & $37 / 40$ \\
\hline & & & BaSO4-20 & -0.24 & 0.04 & & 0.05 & 0.26 & $36 / 40$ \\
\hline \multirow[t]{4}{*}{$\mathrm{BaSO}_{4}$} & At $21^{\circ} \mathrm{C}$ & Experimental precipitate & Average BaSO4-20 & -0.24 & & 0.02 & & & \\
\hline & & & $\mathrm{BaSO} 4-80$ & -0.27 & 0.05 & & 0.03 & 0.26 & $38 / 40$ \\
\hline & & & BaSO4-80 & -0.33 & 0.04 & & 0.03 & 0.26 & $34 / 40$ \\
\hline & & & $\mathrm{BaSO}-80$ & -0.21 & 0.04 & & 0.05 & 0.26 & $47 / 50$ \\
\hline $\mathrm{BaSO}_{4}$ & At $80^{\circ} \mathrm{C}$ & Experimental precipitate & Average BaSO4-80 & -0.27 & & 0.07 & & & \\
\hline $\mathrm{BaSO}_{4}$ & Terrestrial gangue & CH-Lauterbrunnen (Gnadensonne Hauriberg) & LB GH & -0.02 & 0.02 & & 0.07 & 0.23 & $36 / 40$ \\
\hline \multirow[t]{4}{*}{$\mathrm{BaSO}_{4}$} & Terrestrial gangue & China & Chin-1 & -0.39 & 0.03 & & 0.07 & 0.24 & $37 / 40$ \\
\hline & & & G-GH & -0.13 & 0.03 & & 0.09 & 0.26 & $36 / 40$ \\
\hline & & & G-GH & -0.20 & 0.05 & & 0.14 & 0.26 & $37 / 40$ \\
\hline & & & G-GH & $-0.20^{*}$ & 0.03 & & 0.08 & 0.23 & $39 / 40$ \\
\hline \multirow[t]{3}{*}{$\mathrm{BaSO}_{4}$} & Terrestrial gangue & Glücksrad, Harz, Germany & Average G-GH & -0.17 & & 0.05 & & & \\
\hline & & & G-WH & -0.08 & 0.03 & & 0.09 & 0.22 & $39 / 40$ \\
\hline & & & G-WH & -0.05 & 0.03 & & 0.14 & 0.22 & $38 / 40$ \\
\hline \multirow[t]{3}{*}{$\mathrm{BaSO}_{4}$} & Terrestrial gangue & Wolkenhügel, Harz, Germany & Average G-WH & -0.06 & & 0.03 & & & \\
\hline & & & G-SE & -0.03 & 0.04 & & 0.09 & 0.28 & $38 / 40$ \\
\hline & & & G-SE & $-0.07^{*}$ & 0.03 & & 0.14 & 0.27 & $37 / 40$ \\
\hline $\mathrm{BaSO}_{4}$ & Terrestrial gangue & Schlottwitz, Erzgebirge, Germany & Average G-SE & -0.05 & & 0.04 & & & \\
\hline & & & NOR 847 & $-0.15^{*}$ & 0.04 & & 0.07 & 0.41 & $39 / 40$ \\
\hline & & & NOR 847 & $-0.07^{*}$ & 0.03 & & 0.14 & 0.23 & $38 / 40$ \\
\hline $\operatorname{BaMg}\left(\mathrm{CO}_{3}\right)_{2}$ & Terrestrial gangue & Rosh Pinah, Namibia & Average NOR 847 & -0.11 & & 0.09 & & & \\
\hline & & & DEM1 & -0.58 & 0.07 & & 0.02 & 0.32 & $37 / 40$ \\
\hline & & & DEM1 & -0.45 & 0.03 & & 0.02 & 0.24 & $39 / 40$ \\
\hline & & & DEM1 & -0.53 & 0.03 & & 0.02 & 0.24 & $38 / 40$ \\
\hline & & & DEM1 & -0.45 & 0.04 & & 0.02 & 0.32 & $34 / 40$ \\
\hline & & & DEM1 & $-0.53^{*}$ & 0.04 & & 0.09 & 0.25 & $39 / 40$ \\
\hline $\mathrm{BaSO}_{4}$ & Diagenetic barite & Demerara Rise ODP Leg 207 & Average DEM-1 & -0.51 & & 0.05 & & & \\
\hline
\end{tabular}

concentrations of available ligands in the solution, but also at the solution-solid interface. Further experiments regarding this issue as well as the role of foreign element concentrations are under way. In general, the preservation of isotope fractionation in a solid requires the presence of a dissolved reservoir and non-complete precipitation (no reservoir effect).
Stable metal isotope effects have previously been described upon calcite ( $\mathrm{Ca}$ and $\mathrm{Mg}$ isotopes) or barite (Ca isotopes) formation (e.g., Griffith et al., 2008; Tang et al., 2008; Immenhauser et al., 2010). As in the case of $\mathrm{Ba}$, it was generally observed, that the lighter isotopes of $\mathrm{Mg}$ and $\mathrm{Ca}$ are enriched in the solid compared to the dissolved cations, and a rate dependence of isotope discrimination was found. This 


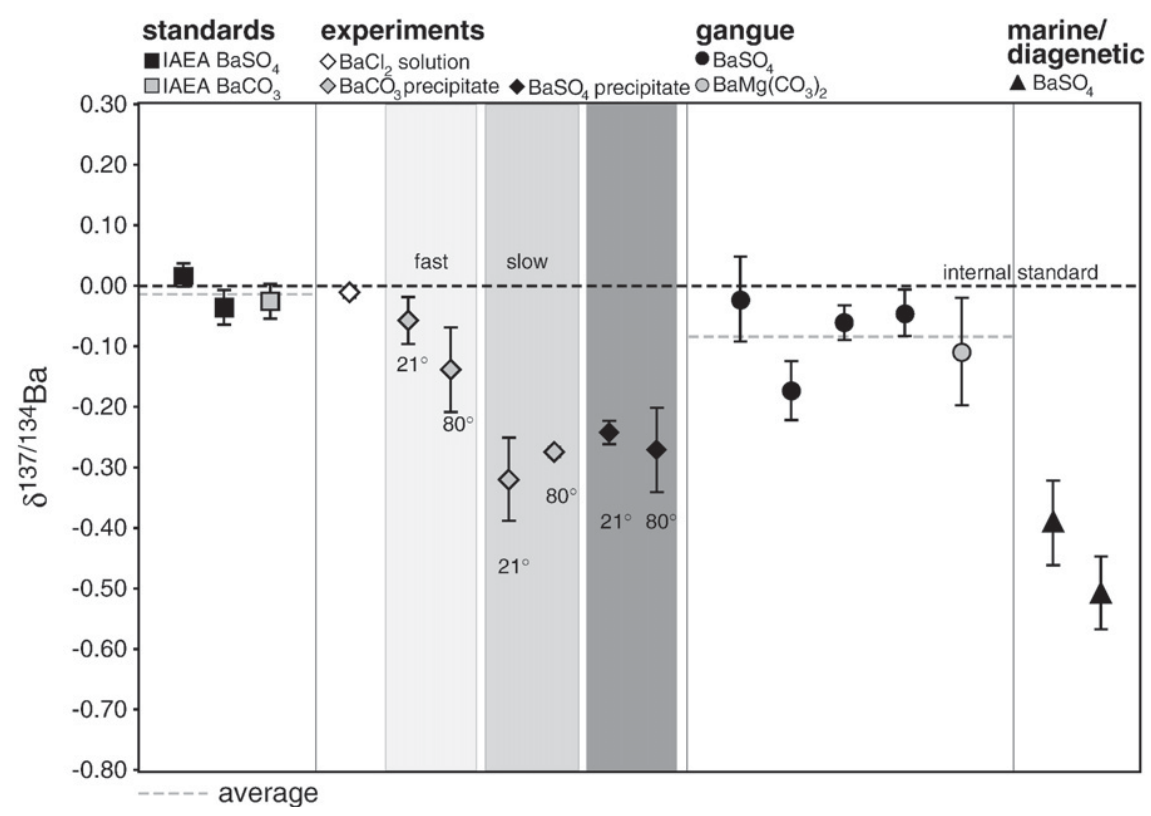

Fig. 2. The experiments were carried out in two different solutions. The precipitates marked with "fast" were precipitated from a $\mathrm{BaCl}_{2}$ solution with $1 \% \mathrm{Na}_{2} \mathrm{CO}_{3}$ solution added slowly. $1 \% \mathrm{NaHCO}_{3}$ solution was slowly added to the $\mathrm{BaCl}_{2}$ solution in the experiments marked with "slow". The $\mathrm{BaSO}_{4}$ precipitates were precipitated from a BaCl $\mathrm{B}_{2}$ solution with $1 \%$ $\mathrm{Na}_{2} \mathrm{SO}_{4}$ solution slowly added. Each experiment was carried out at room temperature $\left(\sim 21^{\circ} \mathrm{C}\right)$ and at $80{ }^{\circ} \mathrm{C}$. Error bars are given as $2 \mathrm{SEM}$ of repeated measurement. For LB GH and Chin-1 (single measurement) the error bar reflects the $2 \sigma$ external sd reproducibility (Table 4$)$.

preferential uptake has been interpreted as results of dehydration of the cation, reaction kinetics, and a surface entrapment of the lighter isotope (Immenhauser et al., 2010). Ba isotope discrimination upon dissolution of isotopically homogeneous Ba carbonate and sulfate, in contrast, is not expected due to the ionic bonds of these salts. The latter hypothesis is supported by the here demonstrated dissolution experiments of $\mathrm{BaSO}_{4}$ that did not reveal any fractionation due to partial dissolution. $\mathrm{BaCO}_{3}$ dissolution was always complete. Experimental and field investigations to further understand the mechanisms behind the observed isotope discriminations in nature are currently under way.

\section{Conclusion}

Static MC-ICP-MS measurements applying double spike technique result in reproducible barium isotopic analyses and reveal differences between terrestrial gangue archives and diagenetic barites. Xe and possible Te interferences can be corrected for. The very low concentration of Te in seawater and continental crust, along with the small ionic radius, do not suggest any significant interference.

Whereas most of the terrestrial gangue samples of different mineralogy result in a $\delta^{137 / 134} \mathrm{Ba}$ value close to the investigated inhouse and international synthetic reference materials, the marine and the diagenetic barite were depleted in the heavy isotope down to $-0.5 \%$ o compared to a Ba nitrate standard solution. The observed $\mathrm{Ba}$ isotope fractionation in experiments and the presumed influence of precipitation rate on the magnitude of isotope discrimination opens routes in understanding the mechanistic base. It is also to be considered, that vital effects may occur upon Ba incorporation into biogenic solid phases such as carbonates or sulfates. Ongoing work focuses on the processes responsible for low temperature isotope discrimination and the effects of physicochemical boundary conditions.

\section{Acknowledgments}

The financial support of the Swiss National Science Foundation (grant 200021-107505) and the University of Fribourg, Switzerland, is acknowledged. Christoph Neururer (University of Fribourg) is kindly acknowledged for SEM analysis of the extraction residue. MEB wishes to thank M. Steinkamm (Deutsche Baryt-Industrie, Bad Lauterberg) for the supply of terrestrial barite samples, and R. Rosenberg for excellent support in the laboratory. Hans-J. Brumsack is further thanked for sampling Leg 207 barites onboard R/V Joides Resolution. The research on ODP Leg 207 barites used samples and data provided by the Ocean Drilling Program (ODP). ODP is sponsored by the U.S. National Science Foundation (NSF) and participating countries under management of Joint Oceanographic Institutions (JOI), Inc. ODP research was funded by Deutsche Forschungsgemeinschaft (grants BO 1584/2 and BR 775/17) and Leibniz Institute for Baltic Sea Research. We kindly acknowledge the comments by two anonymous reviewers.

\section{References}

Andreasen, R., Sharma, M., 2007. Mixing and homogenization in the early solar system: clues from $\mathrm{Sr}, \mathrm{Ba}$, Nd, and $\mathrm{Sm}$ isotopes in meteorites. Astrophysical Journal 665, 874-883.

Arndt, S., Hetzel, A., Brumsack, H.-J., 2009. Evolution of organic matter degradation in Cretaceous black shales inferred from authigenic barite: a reaction-transport model. Geochimica et Cosmochimica Acta 73, 2000-2022.

Böttcher M.E., Dietzel M., 2010. Metal-ion partitioning during low-temperature precipitation and dissolution of anhydrous carbonates and sulfates. EMU Notes in Mineralogy 10,139-187. doi:10.1180/EMU-notes.10.4.

Böttcher, M.E., Gehlken, P.-L., Skogby, H., Reutel, C., 1997. The vibrational spectra of $\mathrm{BaMg}\left(\mathrm{CO}_{3}\right)_{2}$ (norsethite). Mineralogical Magazine 61, 249-256.

Böttcher, M.E., de Lange, G., Brumsack, H.-J., 1998. Sulfate reduction and related stable isotope $\left({ }^{34} \mathrm{~S},{ }^{18} \mathrm{O}\right)$ variations in interstitial waters from the eastern Mediterranean. Proc. ODP, Sci. Results 160, 365-373.

Breit, G.N., Simmons, E.C., Goldhaber, M.B., 1985. Dissolution of barite for the analysis of strontium isotopes and other chemical and isotopic variations using aqueous sodium carbonate. Chemical Geology: Isotope Geoscience section 52, 333-336.

Chan, L.H., Edmond, J.M., Stallard, R.F., Broecker, W.S., Chung, Y.C., Weiss, R.F., Ku, T.L, 1976. Radium and barium at GEOSECS stations in the Atlantic and Pacific. Earth and Planetary Science Letters 32, 258-267.

Church, T.M., 1979. Marine barite. In: Burns, R.G. (Ed.), Marine minerals: Mineralogical Society of America, Reviews in Mineralogy, 6, pp. 175-209.

Edmond, J.M., Measures, C. McDuff, R.E., Chan, L.H., Collier, R., Grant, B., Gordon, L.I. Corliss, J.B., 1979. Ridge crest hydrothermal activity and the balances of the major and minor elements in the ocean - Galapagos data. Earth Planet. Sci. Lett. 46, 1-18.

Eugster, O., Tera, F., Wasserburg, G.J., 1969. Isotopic analyses of barium in meteorites and in terrestrial samples. J. Geophys. Res. 74, 3897-3908.

Ganeshram, R.S., François, R., Commeau, J., Brown-Leger, S.L., 2003. An experimental investigation of barite formation in seawater. Geochimica et Cosmochimica Acta $67,2599-2605$. 
Griffith, E.M., Schauble, E.A., Bullen, T.D., Paytan, A., 2008. Characterization of calcium isotopes in natural and synthetic barite. Geochim. Cosmochim. Acta 72, 5641-5658.

Hartmann, M., Nielsen, H., 1969. $\delta^{34}$ S-Werte in rezenten Meeressedimenten und ihre Deutung am Beispiel einiger Sedimentprofile aus der westlichen Ostsee. Geol. Rundsch. 58, 621-655.

Hidaka, H., Gauthier-Lafaye, F., 2008. Ba isotopic signature for early differentiation between Cs and Ba in natural fission reactors. Geochimica et Cosmochimica Acta 72, 4123-4135.

Hidaka, H., Ohta, Y., Yoneda, S., 2003. Nucleosynthetic components of the early solar system inferred from Ba isotopic compositions in carbonaceous chondrites. Earth and Planetary Science Letters 214, 455-466.

Hidaka, H., Holliger, P., Masuda, A., 1993. Evidence of fissiogenic Cs estimated from Ba isotopic deviations in an Oklo natural reactor zone. Earth and Planetary Science Letters 114, 391-396.

Hippler, D., Villa, I.M., Nägler, T.F., Kramers, J.D., 2004. A ghost haunts mass spectrometry: real isotope fractionation or analytical paradox? Geochimica et Cosmochimica Acta 68, A215.

Hofmann, A., 1971. Fractionation corrections for mixed-isotope spikes of $\mathrm{Sr}$, K, and $\mathrm{Pb}$ Earth and Planetary Science Letters 10, 397-402.

Immenhauser, A., Buhl, D., Niedermayr, A., Riechelmann, D., Dietzel, M., Schulte, U. 2010. Magnesium-isotope fractionation during low-Mg-calcite precipitation in a limestone cave - field study and experiments. Geochim. Cosmochim. Acta 74, 4346-4364.

Johnson, C.M., Beard, B.L., 1999. Correction of instrumentally produced mass fractionation during isotopic analysis of fe by thermal ionization mass spectrometry. International Journal of Mass Spectrometry 193, 87-99.

Johnson, C.A., Emsbi, P., Poole, F.G., Rye, R.O., 2009. Sulfur- and oxygen-isotopes in sediment-hosted stratiform barite deposits. Geochim. Cosmochim. Acta 73, 133-147.

Klump, J., Hebbeln, D., Wefer, G., 2000. The impact of sediment provenance on bariumbased productivity estimates. Marine Geology 169, 259-271.

Langer, G., Nehrke, G., Thoms, S., Stoll, H., 2009. Barium partitioning in coccoliths of Emiliania huxleyi. Geochimica et Cosmochimica Acta 73, 2899-2906.

Li, Y.-H., 1991. Distribution patterns of the elements in the ocean: a synthesis. Geochimica et Cosmochimica Acta 55, 3223-3240.

McCulloch, M.T., Wasserburg, G.J., 1978. Barium and neodymium isotopic anomalies in Allende meteorite. Astrophysical Journal 220, L15-L19.

McManus, J., Berelson, W.M., Klinkhammer, G.P., Johnson, K.S., Coale, K.H., Anderson, R.F., Kumar, N., Burdige, D.J., Hammond, D.E., Brumsack, H.J., McCorkle, D.C., Rushdi, A., 1998. Geochemistry of barium in marine sediments: implications for its use as a paleoproxy. Geochimica et Cosmochimica Acta 62, 3453-3473.
Nier, A.O., 1938. The isotopic constitution of strontium, barium, bismuth, thallium and mercury. Physical Review 54, 275.

Parrington, J.R., Knox, H.D., Brenemann, S.L., Baum, E.M., Feiner, F. (Eds.), Nuclides and Isotopes, Chart of the Nuclides, 64 pp., KAPL Inc., Lockheed Martin, Schenectady, N.Y., 1996.

Paytan, A., Griffith, E.M., 2007. Marine barite: Recorder of variations in ocean export productivity: Deep-Sea Research: Part II. Topical Studies in Oceanography. doi:10.1016/ j.dsr2.2007.01.007

Puchelt, H., 1967. Zur Geochemie des Bariums im exogenen Zyklus. Sitzungsber Heidelb. Akad. Math. Wiss. Nat. Kl. 4, 85-205.

Pujol, M. Marty, B., Burnard, P. Philippot, P. 2009. Xenon in Archean barite: weak decay of ${ }^{130} \mathrm{Ba}$, mass-dependent isotopic fractionation and implication for barite formation. Geochimica et Cosmochimica Acta 22, 6834-6846.

Ranen, M.C., Jacobsen, S.B., 2006. Barium isotopes in chondritic meteorites: implications for planetary reservoir models. Science $314,809-812$.

Reitz A., Pfeifer, K., de Lange, G.J., Klump, J., 2004. Biogenic barium and the detrital Ba/Al ratio: a comparison of their direct and indirect determination. Marine Geology 204 289-300.

Rudnick, R.L., Fountain, D.M., 1995. Nature and composition of the continental crust: a lower crustal perspective. Reviews in Geophysics 33, 267-309.

Rudnick, R.L, Gao, S. 2004. Composition of the continental crust. In: Holland, H.D. Turekian, K.K. (Eds.), Treatise on Geochemistry, 3. Elsevier, Amsterdam, pp. 1-64.

Siebert, C., Nägler, T.F., Kramers, J.D., 2001. Determination of molybdenum isotope fractionation by double-spike multicollector inductively coupled plasma mass spectrometry. Geochemistry, Geophysics, Geosystems 2 2000GC000124.

Steyn, J.G.D., Watson, M.D., 1967. Notes on a new occurrence of norsethite. The American Mineralogist 52, 1770-1775.

Tang, J., Dietzel, M., Böhm, F., Köhler, S., Eisenhauer, A., 2008. $\mathrm{Sr}^{2+} / \mathrm{Ca}^{2+}$ and ${ }^{44} \mathrm{Ca} /{ }^{40} \mathrm{Ca}$ fractionation during inorganic calcite formation. II. Ca isotopes. Geochim. Cosmochim. Acta 72, 3733-3745.

Torres, M.E., Brumsack, H.J., Bohrmann, G., Emeis, K.C., 1996. Barite fronts in continental margin sediments: a new look at barium remobilization in the zone of sulfate reduction and formation of heavy barites in authigenic fronts. Chem. Geol. 127, 125-139.

Wedepohl, K.H., 1995. The composition of the continental crust. Geochimica et Cosmochimica Acta 59, 1217-1232.

Wortmann, U.G., Chernyavsky, B., Bernasconi, S.M., Brunner, B., Böttcher, M.E., Swart, P.K. 2007. Oxygen isotope biogeochemistry of pore water sulfate in the deep biosphere: dominance of isotope exchange reactions with ambient water during microbial sulfate reduction (ODP Site 1130). Geochim. Cosmochim. Acta 71, 4221-4232. 